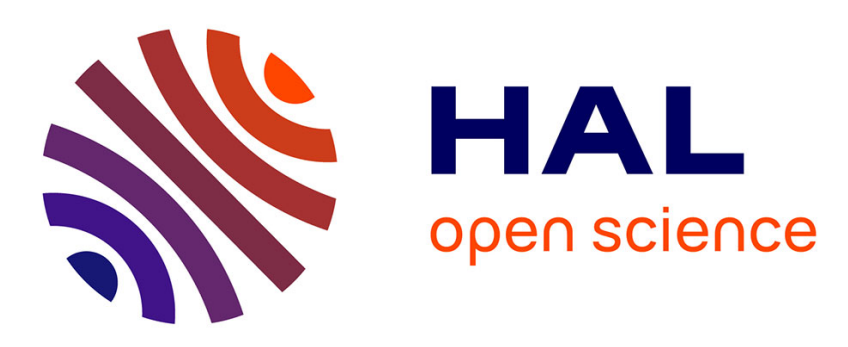

\title{
Lived experience as a unit of analysis for the study of learning
}

Gilles Dieumegard, Sandra Nogry, Magali Ollagnier-Beldame, Perrin Nicolas

\section{To cite this version:}

Gilles Dieumegard, Sandra Nogry, Magali Ollagnier-Beldame, Perrin Nicolas. Lived experience as a unit of analysis for the study of learning. Learning, Culture, and Social Interaction, Elsevier, 2019, 10.1016/j.lcsi.2019.100345 . halshs-02270860

\section{HAL Id: halshs-02270860 https://halshs.archives-ouvertes.fr/halshs-02270860}

Submitted on 2 Dec 2021

HAL is a multi-disciplinary open access archive for the deposit and dissemination of scientific research documents, whether they are published or not. The documents may come from teaching and research institutions in France or abroad, or from public or private research centers.
L'archive ouverte pluridisciplinaire HAL, est destinée au dépôt et à la diffusion de documents scientifiques de niveau recherche, publiés ou non, émanant des établissements d'enseignement et de recherche français ou étrangers, des laboratoires publics ou privés. 


\title{
Lived experience as a unit of analysis for the study of learning
}

\author{
G. Dieumegard ${ }^{a}$,, S. Nogry ${ }^{b}$, M. Ollagnier-Beldame ${ }^{c}$, N. Perrin ${ }^{d}$ \\ a University of Montpellier, LIRDEF (EA 3749), France \\ ${ }^{\mathrm{b}}$ University of Cergy-Pontoise, PARAGRAPHE (EA 349), France \\ ${ }^{\mathrm{c}}$ CNRS, ICAR (UMR 5191), France \\ ${ }^{\mathrm{d}}$ University of Teacher Education, Lausanne, Switzerland
}

\section{A R T I C L E I N F O}

\section{Keywords:}

Experience

Learning process

First person perspective

Enaction

Micro-phenomenology

Situated cognition

Socio-cultural approaches

\begin{abstract}
A B S T R A C T
To study individual features of a learning activity entangled in a material and social environment, we adopt lived experience as a fundamental unit of analysis. Defined as an ongoing process which is known "from within" by individuals, lived experience derives from the phenomenological tradition and is rooted in the enactive approach of cognition. As such, lived experience appears to be active and passive, holistic, situated in a complex temporality, and partly pre-reflective. The study of lived experience of learners requires the researcher to adopt a second-person perspective in which $\mathrm{s} /$ he constitutes descriptions of lived experience through a relational process. We present two second-person methods for collecting data: explicitation and self-confrontation interviews. Two case studies illustrate the implementation of these methods: the first focuses on sensorial experience in swimming lessons, and the second concerns understanding in teacher training.

Endorsing lived experience as a unit of analysis allows thinking anew the consideration of the individual into socio-cultural approaches of learning.
\end{abstract}

\section{Introduction: thinking anew the individual in sociocultural approaches}

Research examining the unit of analysis in learning and education usually contrasts two types of approaches: cognitive and sociocultural approaches (Mason, 2007; Säljö, 2009). In cognitive approaches, the unit of analysis is individual - meaning, specifically, the cognitive structures of subjects and the information processing mechanisms they perform. In sociocultural approaches, associating situated, pragmatist and cultural-historical perspectives, the unit of analysis is mostly collective - in the sense, specifically, of the situated activity constructed by several individuals in a material and social world.

Strictly abided by, each of these types of approaches provides a partial view of learning (Sfard, 1998). For example, sociocultural approaches adopt theoretically an externalist conception, stating that cognition and learning occur, at least partially, outside the individual subjects. Thus, they shed light on important material, collective and social aspects of learning, such as meaning-making practices, cognitive apprenticeship or activity systems. But they also tend to understate some other aspects that are addressed by the cognitive approaches at an individual level, as for example abstraction, transfer or conceptual change. Consequently, several authors question the theoretical possibility for bridging sociocultural and cognitive approaches (among others, Alexander, 2007; Greeno, 1998; Mason, 2007).

Methodologically, sociocultural approaches lead to observations consistent with the externalist statement. They often focus on

\footnotetext{
* Corresponding author.

E-mail address: gilles.dieumegard@umontpellier.fr (G. Dieumegard).
} 
manifest collective activity in authentic learning settings as informed by the analysis of video data (Derry et al., 2010; Jordan \& Henderson, 1995). Nevertheless, in most of times, there are many non-manifest dimensions of individual activity - such as what each learner is concerned about, how s/he perceives a situation, what $\mathrm{s} /$ he pays particular attention to and the meaning s/he constructs at a moment - which are scarcely informed by video data alone.

To gain more access to individual activity taking into account its situated feature in a rich material and social environment, we propose to adopt lived experience as a fundamental unit of analysis. Lived experience is defined as an individual ongoing process known "from within". It is conceived through enactive theory, particularly the theoretical strand that related it to phenomenology (Depraz, Varela, \& Vermersch, 2003; Varela, Thompson, \& Rosch, 1991).

In relation to the theme of this special issue, adopting lived experience as a unit of analysis affords to think anew the incompleteness of sociocultural approaches, and the possibilities they offer for exploring learning and knowledge at an individual level. To this end, (a) we define lived experience in the theoretical perspective of enactivism and phenomenology, and develop the principal features of this unit of analysis; (b) we give an overview of the methods suited for studying lived experience, by distinguishing first, second, and third person perspectives, and by introducing the techniques of explicitation interviews, self-confrontation interviews, and the procedures for analyzing the data; (c) we present two case-studies endorsing lived experience as a unit of analysis in different contexts (swimming lessons and teacher training); (d) we discuss the extent to which the unit of analysis of lived experience fits and enriches the sociocultural approaches: in particular, we compare our enactivist-phenomenological approach from another defining experience from Dewey's and Vygotsky's theories (Jornet, Roth, \& Krange, 2016; Roth \& Jornet, 2014).

\section{Lived experience as unit of analysis}

In the enactive theory, "cognition is not the representation of a pregiven world by a pregiven mind but is rather the enactment of a world and a mind on the basis of a history of the variety of actions that a being in the world performs" (Varela et al., 1991, p. 9). This postulation opposed to the habitual cognitive statement originates from research in biology showing that the interactions between an organism and its environment are asymmetrical, in the sense that they are determined by the structure and the history of the organism itself (Maturana \& Varela, 1980). This principle of asymmetry has led to take into account experience in the study of human cognition (Varela et al., 1991), and to relate it with Husserlian phenomenology (Depraz et al., 2003).

Various traditions of phenomenological psychology have been developed. They have in common to be founded as alternatives to classical psychology aiming at the reductionist canons of natural sciences. All phenomenological approaches elaborated epistemologies and methods to study the human being holistically and to consider all its complexity (Giorgi, 2014; Vermersch, 2012). To this end, they trust subjectivity through taking into account in research what the subject lives, her lived experience. Therefore, in Depraz et al. (2003, p. 2), experience is defined as "the lived, first-hand acquaintance with, and account of, the entire span of our minds and actions, with the emphasis not on the context of the action but on the immediate and embodied, and thus inextricably personal, nature of the content of the action. Experience is always that which a singular subject is subjected to at any given time and place, that to which $\mathrm{s}$ /he has access "in the first person'."

Individual experience is seen as unfolding within the context of social and material interactions in which a subject is engaged and under the conditions defined by the subject's physical state at a given moment in time. The study of the influence of the environment on human development is central to Husserl's work, with the concept of Erlebnis, usually translated as "lived experience". Thus, a subject living an experience is an "I" who is not merely a consciousness directed at the world, but is also a being affected by the world. According to Depraz et al. (2003), whose work is based on the Husserlian phenomenology, the subject is immersed in a dual active/ passive movement or process. The same dual movement can be found in Henry, according to whom the subject living an experience is to be seen as being immersed in an inter-affection: the subject affects the world just as much as the world affects her/him (Henry, 2008, in de Jaegher, 2015). In this paper, we use the term "affect" in the phenomenological sense, i.e. how a situation, or an environment, "does something" to a subject, with no direct causation, but rather from a perspective of reciprocal begetting of the "affecting" and the "affected". Heidegger also describes the passive dimension of experience when he writes that the subject is not an operator of experience but is rather in a relation of welcoming and letting-go of the experience that presents itself to her/him (Heidegger, 1971). According to enactive theory in which our proposal is rooted, experience is coupled with action. Inseparable from experience, action, which is the basis for perception, is either intentional or unintentional. In both cases, experience is never pure passivity, but a combination of active and passive movement towards the world.

Given this dual feature of experience as both active and passive, experience needs to be understood and construed from a relational point of view. According to Husserlian phenomenology, the subject experiences the world through an intentional relation that integrates consciousness and phenomena. Reality is a lived world - an experienced world - that invariably presents itself to the subject from a particular perspective. The subject-object distinction may also be viewed from the perspective of subject experience. The relational perspective described here is similar to Nagel's approach (1974), for whom a living being's experience of the world refers in reality to the appearance of things in the eyes of that being - a phenomenon in the etymological sense of the term, an appearance, i.e. what defines the living being as a being.

When a phenomenon presents itself to a subject, that subject's experience is a holistic experience. In other words, an experience is a combination of different elements that cannot be easily separated. Vermersch (1994) distinguishes between different layers of lived experience, i.e. the fact that every lived experience contains or implies cognitive, emotional, motor, motivational, identity and spiritual dimensions (among other dimensions). These distinctions remind us of the four "experiential threads" defined by Mc Carthy and Wright (2004): the sensual thread (sensory engagement with a situation), the emotional thread (meaning given to an object or person on account of our values, objectives and desires), the composition thread (relations between the parts and the whole of an experience) 
and the spatio-temporal thread of the experience (its links to the past and the future).

Mc Carthy's and Wright's (2004) fourth experiential thread emphasizes an essential component of experience: time. In other words, the holistic nature of experience includes its rootedness in time. It implies that experience is to be construed singularly, i.e. by studying a particular moment in time. Otherwise, we would be dealing with a class of experience or a generality. Crucially, experience is specific, concrete and individuated, centred on, or structured around, its particular spatio-temporal parameters, making it invariably new and different (Depraz et al., 2003). From a phenomenological perspective, we focus on the study of things as they appear in experience, in the present moment, in a micro-temporality. But although lived in the present, it integrates the past and the future (Stern, 2004). For Husserl, in the present, we find echoes of the past, or retentions. These echoes or retentions are the immediate past, the echo of which can be heard in the present moment, like a "comet's tail". There is also a future experienced in the present, or protensions, pointing to the predictable or implicit immediate moment in what has already occurred in the past and in the present. Retentions and protensions form part of lived experience in the present. These aspects of experience emerge, subjectively, as a global, cohesive, unified and unique experience taking place in a subjective 'now' (Stern, 2004; Varela, 1999).

Lived experience mobilizes different types of consciousness. It is partly rational and considered, involving, in other words, the subject's reflective consciousness: the subject "is conscious" of experiencing something and can easily report it. A different dimension of lived experience remains beneath the threshold of reflective consciousness - a "pre-reflective" dimension not directly accessible to the consciousness of the subject experiencing it. The non-reflective dimension of consciousness described by Piaget (1976) as "consciousness in action" concerns everything that affects the subject passively and which may re-emerge. A similar conception is present in what Theureau (2006) terms "pre-reflective consciousness", i.e. anything that can be reported about every instant of a past situation, in favourable conditions for reporting.

Thus, choosing lived experience as a unit of analysis means:

- to focus individually, as a starting point, on each subject, but also to take into account the social and material levels, through their subjective resonance;

- to consider experience from a relational point of view, given that during an experience, the subject affects the world just as much as the world affects her/him;

- to take into account the interwoven dimensions of experience (e.g. cognitive, emotional, motor, motivational dimensions);

- to study the hic et nunc experience through a particular moment for the subject, temporally situated and as integrating past and future.

More broadly, this choice implies in a first time to describe what makes sense for a given subject at a given moment, and in a second time to characterize what is 'the experience of something', i.e. 'what it is like to...' based upon the analysis of several experiential descriptions.

\section{How to study lived experience}

\subsection{Perspectives in 1st, 2nd and 3rd person}

Studying lived experience from within requires a specific epistemology and rigorous methodologies. Phenomenological approaches draw a distinction between first-person, second-person and third person perspectives by contrasting the point of view of the subject in question with the point of view of another subject and, more generally, subjects' independent perspectives (Depraz et al., 2003).

The first-person perspective is characteristic of experience as it is accessed by the subject. In other words, it is the subject's perspective. In a scenario where a researcher collects data about her/his own experience, we speak of a perspective or posture that is 'radically' in first person to denote the idea that the data are drawn from the researcher's own lived experience.

The second-person perspective implies "enabling the gathering of 'first person' data, i.e., data that express the viewpoint of the subject herself, in the grammatical form 'I...'. But since the data have been gathered through another person (a 'You'), the method has been dubbed 'second person'" (Petitmengin, 2006, pp. 230-231). This perspective implies a combination of empathic resonance and heterophenomenological observation (Depraz, 2012), i.e. an inference from behaviours (whether linguistic or other behaviours such as gestures and other forms of semiosis). For all that the delimitation of what is observed is not fixed, the idea is that a second-person perspective is intersubjective and allows for an indirect point of view on the subjective perspective.

The third-person perspective does not allow for the study of experience since it takes behaviours as its object and examines them according to predefined categories. The other is delimited from the outside and is reduced to fact (Bitbol, 2014). This perspective implies a third-person epistemology in which subjectivity and lived experience are generally viewed as epiphenomena or as being beyond the reach of science (Vermersch, 2000). The main reason for this is the lack of confidence in the validity of the data drawn from introspection (Nisbett \& Wilson, 1977), although such data have recently been given renewed legitimacy by several studies (Hurlburt \& Schwitzgebel, 2007; McAuliffe \& McGann, 2016; Petitmengin, Remillieux, Cahour, \& Carter-Thomas, 2013).

\subsection{Perspectives, epistemologies and methods}

Taking lived experience as a unit of analysis from a first-person perspective does not mean adopting a solipsistic approach. In any research process, intersubjective coordination is in operation (Depraz et al., 2003; Maturana, 2000). Data collection and analysis involve the construction of categories that can be shared between the subject and the researcher. In this sense, a perspective implies an 
epistemology.

It is vital to bear in mind that it is not an epistemology of immediacy since experience, while it may be lived and familiar, has a prereflective dimension. Knowing it in detail presupposes an objectivation of one's subjectivity - no easy task despite the apparent transparency of intimacy and familiarity. Thus, the first- and second-person perspectives should not be confused with immediate donation, i.e., for the subject, a sudden, clear and distinct illumination (Vermersch, 2000). "Indeed, being epistemically related to facts about oneself ('I') is not a sufficient condition for first-person perspective taking: You can also have an objective, third-person view on your headache. [...] What is needed is a difference not in terms of the epistemic object but, rather, in terms of epistemic access - even if it may turn out to be necessary to refer to specific epistemic objects in order to clarify what the specific kind of access is. The decisive point seems to be that there are certain features of oneself that do require a specific kind of epistemic access" (Pauen, 2012, pp. 37-38).

We present below two second-person interview methods, explicitation and self-confrontation interviews. Both involve the subject's re-presentification of her mental and bodily states, a basic self/other distinction and a basic awareness of the relevant situational differences between the subject and the other being. In both, what is said by the subject deploys lived experience in its various layers, these facets being related to an experience that is effectively lived and is therefore, by definition, singular. In both cases, since the researcher is collecting the words of a subject other than herself, these methods provide a route to highlighting "a perspective on a perspective".

\subsection{Second-person methods: explicitation and self-confrontation interviews}

Accounting for one's own experience is not a given (Depraz et al., 2003), studying lived experience in second person perspective requires specific methodology. In this section, we present two second-person interview methods, explicitation and self-confrontation interviews. In both, the intervention of the researcher aims to direct the subject's attention to her/his lived experience during a singular past situation and to describe it.

\subsubsection{Explicitation interview method}

The explicitation interview, also known as micro-phenomenological interview, was developed and tailored over the range of several decades by Vermersch $(1994,2012)$ and Petitmengin (2006). Connecting several theoretical frameworks - notably Piaget's theory of consciousness, Gusdorf's theory of affective memory and Husserl's phenomenology - the explicitation method lies at the heart of an applied approach to psycho-phenomenology. It consists in 'guided retrospective introspections', the aim being to accompany an interviewee in recalling a past situation in order to build a detailed and holistic description of her lived experience during that situation. Such a description is holistic because the interviewer, since s/he is interested in the experience as a whole, questions its various threads (the cognitive operations of the interviewee, her physical actions, sensations and emotions). The temporal dimension of experience is carefully investigated, decomposing larger-scale experiences into series of highly fine-grained phenomena. A "fragmentation" phase is followed by a "qualitative expansion" phase: each micro-moment is investigated along the various threads of experience. One of the foundations of explicitation interview method is to address a singular past situation lived by the interviewee (even if $\mathrm{s} /$ he has recurrently lived similar experiences) in order to collect specific descriptions rather than generalizations about what was formerly lived. The described moment or instant being chosen in consultation with the subject and integrated within a very short and specific timeframe (or temporality), ranging from just a few seconds to several minutes of activity. The collection process implies placing and maintaining the interviewee in a specific and non-spontaneous speech posture named 'embodied posture of speech'. This attitude enables a presence to herself and leads to an intimate contact with the past situation under study, and then to a quasi-reliving of it, through its re-presentification. The interviewee's first-person data are thus obtained from the interviewer's questions and guidance, which explains why the explicitation interview technique is defined as a second-person method (Petitmengin, 2006).

\subsubsection{Self-confrontation interview method}

Self-confrontation interviews are similar to stimulated recall interviews (Lyle, 2003) in which subjects are supposed to accurately "re-live" a past situation through many clues. Here, a researcher is looking for a dynamic recontextualization of the subject through traces - mostly, video recordings (Theureau, 2010). These traces of the subject's behaviour provide her with clues about her environment, moment by moment. In these conditions, the subject can access her former experience and verbalize at any moment. Crucially, the researcher does not direct the delimitation of the object but only the attention of the subject. Self-confrontation interviews benefit from advances about 'embodied posture of speech' in explicitation interviews (Vermersch, 1994). The prompting focuses on the expression of the experience by inviting the subject to say what s/he was doing, thinking, concerned about, taking into account and perceiving or feeling at each moment. This explains why the interview questions address the description of events and actions as they are experienced by the subject in a singular videotaped episode, focusing on "what" was experienced and "how".

To maximize the validity of these data, the researcher has to take precaution: 1) minimize the time delay between the original episode and the interview; 2) reduce the anxiety of the agent; 3) limit the perception of judgmental probing; 4) allow relatively unstructured responses; and 5) avoid the possibility for the agent to keep "explaining" and thus moving away from an embodied posture of speech.

Both interview methods involve the subject's re-presentification of her mental and bodily states, a basic self/other distinction and a basic awareness of the relevant situational differences between the subject and the other being. In both, what is said by the subject give access to lived experience in its various layers, these facets being related to an experience that is effectively lived and is therefore, by definition, singular. In both cases, since the researcher is collecting the words of a subject other than herself, these methods provide a route to highlighting "a perspective on a perspective" (Pauen, 2012). 


\subsection{Data analysis}

The researcher has to manage a twofold purpose: the necessity to understand each subject perspective in an empathetic and idiosyncratic manner and the production of more general results. Once an interview has been realized and transcribed, a work of reorganization, analysis, and abstraction is necessary to highlight the characteristics of the lived experience.

At the first stage, the researcher has to keep close to the subject's perspective in order to validly account for lived experience. S/he has to achieve a comprehensive analysis integrating the subject's categories. In a synchronic approach, the researcher has to describe the different interwoven threads of experience and to clarify what makes sense for the subject at each moment. In a diachronic approach, the researcher has to highlight the dynamic characteristics of experience: how learners experience unfolds over time?

When the study focuses on subjects experiencing the same situation (e.g. a collaborative task or an exchange between professor and learners), another stage of analysis consists in aligning moment by moment the descriptions of their experience. This temporal alignment allows considering articulations between them.

Otherwise, if the objective is to construct a generic representation of the common structure of experience, the researcher has to revisit the descriptions produced by comprehensive analysis and compare them by constructing and using a precise and standardized coding scheme based on a limited number of categories. In achieving such comparative analysis, the researcher moves away from each subject's perspective to the extent to which the analytic categories 1) depend on the research question, 2) are restrictive and 3) may be meaningless for the subjects.

In sum, metaphorically the researcher moves closer to (comprehensive analysis) and then moves away (comparative analysis) from each subject's perspective.

\section{Case studies}

We propose to show the interest of adopting lived experience as unit of analysis in learning research by presenting two case studies. The first case study focuses on swimming lessons at college $e^{1}$ (Lémonie, Light, \& Sarremejane, 2016), the aim of the study being to highlight how student-teacher interactions affect the sensorial experience of students. It uses the explicitation interview method. The second case study (Dieumegard \& Perrin, 2014) concerns a teacher training program at university. The aim was to understand the dynamics of learner understanding through self-confrontation interviews.

\subsection{The evolution of lived experience in a swimming lesson}

The first case study is focused on swimming learning at middle school (Lémonie et al., 2016). The research question was: how does the dual interaction between a teacher and a student affect the latter's experience and does it contribute to the reorganization of this experience?

Here, teacher-student interaction was examined from an enactivist perspective as a process in which both continually and mutually adjust their actions and their intentions in relation to the other, the actions and communications of one thus becoming potential sources of disruption to the other. This was addressed, first, by analyzing the lived experience of both the teacher and the student during the interaction and, second, by contrasting the description of the lived experience of the student before and after this interaction situation.

To this end, post-session explicitation interviews were conducted on different episodes experienced during the session (swimming sequences, teacher observations, teacher-student interactions) selected by the researcher. In this study, choosing lived experience as a unit of analysis enables to highlight the private dimension of action, particularly the sensual threads of experience: what is smelt, felt, seen, heard and touched by the subject in situ.

During the learning session presented to illustrate our approach, the task consisted of swimming a length of the pool in backstroke with the board "above the head" while trying to keep the "arms stretched out". During the exercise, the teacher identified one student Fanny - who was struggling to carry out the task. In the post-session interview, Fanny expressed her experience during the exercise as follows:

"I was holding the board, I had my arms stretched out and I was starting to sink"; "when the water started covering my face I stopped"; "it sounded as if a container were filling up"; "I stop, I stand up, I'm not looking at that particular moment. It's getting on my nerves, I can't do it!"

In her description, Fanny used the metaphor of a container filling up and the word "sink" - i.e. linguistic cues associated with significant emotional investment.

From the teacher's point of view, Fanny was not comfortable with the exercise. He then began an exchange with the student, asking her questions to understand the reason why she felt she had struggled, and to lead her to find a solution. Initially, the exchange was unsuccessful, with the teacher failing to perceive the significant emotional involvement experienced by the student, who remained convinced that she would not be able to complete the task. Then the teacher sought to understand the reasons for this lack of understanding by putting himself in the student's shoes (Table 1 ).

Based on a perspective of empathy with the student and of understanding of her subjective experience, such interactions serve to

${ }^{1}$ College is the equivalent of middle school in the French educational system. Students are aged 11-15 or 16. 
promote the construction of a space shared by the teacher and the student that leads to the articulation of possible solutions. The student is thus able to truly hear what the teacher is suggesting.

Teacher-student interactions help the student to succeed in the task and contribute to altering the sensorial experience. Following this exchange, she described her lived experience during the backstroke as follows:

"I eventually managed to do it", "The water wasn't really on my face", "my ears are in the water", "I can't hear anything".

It is not merely that the interaction affects Fanny's observable behaviour. It also introduces new knowledge about the action "eventually the head comes up anyway" and transforms her subjective experience of immersion in water. The sensation of drowning and the perceptions associated with the metaphor of container filling are no longer present.

In such a study, choosing lived experience as a unit of analysis provides a comprehensive approach to what is at play in an interaction not by analyzing interactions themselves but rather by documenting the lived experience of two protagonists during the interaction. It gives access to the private character of experience - i.e. to the concerns, feelings, thoughts of subjects and to the meaning they give to the actions or words of others. It also documents how action, cognitive and sensual threads of experience are affected by such interactions.

\subsection{Understanding in a course about lesson planning}

In the enactive perspective, knowledge is seen as the experience of coherence linking elements of present experience and elements of one or several past experiences (Maturana, 2000). It is expressed as a sense of familiarity, regularity and "déjà-vu" transcending the here and now. Such familiarity is viewed in relation to distinctions, which are identifications of entities (situations, elements, processes, etc.) and the relations between them (Maturana, 2000; Maturana \& Varela, 1980). In the second case study, tracing distinctions is useful for investigating understanding.

The data were collected in a course about lesson planning delivered as part of a teacher education program offered in Switzerland. During the course, students were taught about the concepts of "instructions", "task", "activity" and "learning" to demonstrate how the concepts can be used in their lesson planning practices (Dieumegard \& Perrin, 2014).

Several data sets formed a multi-folded corpus including: (1) video-recordings of each session of the course allowing for observation of the behaviours of both the teacher and the students, slides on the beamer and teacher's writings on the blackboard; (2) selfconfrontation interviews of the teacher and three voluntary students; and (3) copies of the documents given by the teacher and copies of students' notes as well. (Table 2).

A third-person description of the activity of Student 3 based solely on these behavioural data indicates that she attended the teacher's presentation and reported in her notebook some aspects of what was discussed and presented, but we do not known anything about her understanding. The self-confrontation data serve to enlighten this silent activity (Table 3).

In the analysis of such data, the first operation involves identifying successive units representing what Student 3 experienced as her own activity. To do so, we begin by determining temporal boundaries to delimit the units before labelling each of them. This identification of units is iteratively processed by integrating previous and subsequent units to form a plausible course of experience (Table 4).

For the study of Student 3's understanding, we identify knowledge elements representing relations between entities (objects, events, processes, situations, words, expressions, etc.) and properties (qualities of entities or relations with other entities) experienced at a given moment as regularities. Entities are shown in square brackets and properties after a colon (Table 5).

We identified units and knowledge elements in both the Teacher and in Students 1, 2 and 3. However, a second step in the analysis is necessary in order to generate interpretations that go beyond the idiosyncrasy of each individual description. To this end, we consider what is habitually referred to as individual understanding as a primordial manifestation of intersubjective coordination. In a course, students are expected to "follow what the teacher says". Therefore, we need to identify the set of knowledge elements that are both experienced and expressed by the teacher and consider it as a reference. Elements of knowledge experienced by students may also reveal the extent to which students have understood the teacher. We define three analytical categories: 1) overlap (sufficient similarity between the teacher's and student's knowledge elements); 2) precursor (a student's knowledge element differs from the teacher's, although there is potential for overlap); 3) unconnected (no apparent connection between the knowledge elements of the teacher and the student). We also identify when they experienced discrepancies between different knowledge elements.

Analysis at an intersubjective level reveals that tortuous paths of understanding are common beneath the apparent simplicity shown by behavioural data.

First, students experience discrepancies (for example, in Units 26 and 27 in the case of Student 3) between what they perceive in a

Table 1

Extracts of explicitation interviews about the interaction between the teacher and Fanny conducted with each protagonist.

\begin{tabular}{|c|c|}
\hline Teacher's verbatim & Fanny's verbatim \\
\hline $\begin{array}{l}\text { I feel it's not conceivable for her because she's going to sink. } \\
\text { I infer that for her, what she's thinking when her head goes beneath the surface of } \\
\text { the water is, "I'm sinking but there's no end to it - in other words I keep sinking } \\
\text { and if I don't stop I'll continue to sink even further, and in any case, I won't go } \\
\text { back up to the surface". } \\
\text { I say, "when your head is beneath the surface of the water you keep swimming, you } \\
\text { can hold your breath while you keep moving and you'll see that your head will go } \\
\text { back up above the surface of the water". }\end{array}$ & $\begin{array}{l}\text { He told me it doesn't matter because in any case it's a gradual thing and } \\
\text { after a while the head returns above the surface of the water anyway. }\end{array}$ \\
\hline
\end{tabular}


Table 2

Excerpt of video in classroom and notes: example of Student 3.

\begin{tabular}{|c|c|}
\hline Time & Video-recording in classroom \\
\hline & $\begin{array}{l}\text { [Between 15:03 and 15:58, the teacher presented a distinction between "movement/body } \\
\text { activity" and "intellectual/mental activity"] }\end{array}$ \\
\hline $15: 58$ & Yes? [turning towards S2 who raised the hand] \\
\hline & Student 2: Sorry, but I don't understand movement, intellectual and mental. Does it mean \\
\hline 16:07 & you can see movement and intellectual? \\
\hline & $\begin{array}{l}\text { Teacher: No, you can't see it, but when you prepare a task for your pupils, there's a part of } \\
\text { what you imagine they will do which is visible, with some movements being more tied to the } \\
\text { body. } \\
\text { If they cut something, you'll see them cutting, you'll see them pasting. You can describe all } \\
\text { these movements. }\end{array}$ \\
\hline $16: 43$ & $\begin{array}{l}\text { But your focus is also on an intellectual or mental activity, things that happen in the mind. } \\
\text { When they paste the pictures, your purpose - your objective - is to make them observe the }\end{array}$ \\
\hline $17: 00$ & $\begin{array}{l}\text { pictures to identify the common features in order to paste them. And that, you can't see. } \\
\text { But for you, it's important to know that these activities have to be set in motion, otherwise } \\
\text { you can't help the pupils who precisely aim at doing, rather than engaging in an activity } \\
\text { allowing learning. } \\
\text { [throughout the exchange, Student } 3 \text { alternated between note-taking and looking at what } \\
\text { was projected onto the screen] }\end{array}$ \\
\hline \multicolumn{2}{|c|}{ Notes taken by Student 3} \\
\hline & ment / intellectual / \\
\hline & (2) \\
\hline & Moutale \\
\hline
\end{tabular}

Table 3

Self-confrontation data: example of Student 3.

\begin{tabular}{|c|c|c|c|}
\hline Time & Video recording in classroom & Time & Self-confrontation interview of Student 3 \\
\hline $15: 58$ & $\begin{array}{l}\text { Student 2: Sorry, but I don't understand } \\
\text { movement, intellectual and mental... }\end{array}$ & $39: 26$ & $\begin{array}{l}\text { After that, I said to myself, intellectual, that's not visible, but in that case, how can we } \\
\text { give them a mark? We grade, so to speak, something intellectual when we give a mark to } \\
\text { a pupil. So I told myself, I'll try to listen to what she says, because I don't see why we } \\
\text { can't see it. }\end{array}$ \\
\hline $16: 18$ & $\begin{array}{l}\text { Teacher: If they cut something, you'll see them } \\
\text { cutting, you'll see them pasting... }\end{array}$ & $39: 54$ & $\begin{array}{l}\text { I said to myself, "Oh yes, because we see he did that" - for example, we see someone } \\
\text { passing a test, he notes down some elements, we see he did make an effort - but } \\
\text { nevertheless, movement, for me... It's more intellectual, I wasn't necessarily happy with } \\
\text { the idea. }\end{array}$ \\
\hline $16: 24$ & $\begin{array}{l}\text { But your focus is also on an intellectual or } \\
\text { mental activity... }\end{array}$ & $40: 24$ & $\begin{array}{l}\text { I told myself, "Oh yes", but actually we can't see what is going on inside our heads, we } \\
\text { can see it on the paper, but it's not necessarily what actually happened, it's a process } \\
\text { they have. So really, I understood why it's not visible. }\end{array}$ \\
\hline $\begin{array}{l}16: 43 \\
17: 00\end{array}$ & $\begin{array}{l}\text { But for you, it's important to know that those } \\
\text { activities have to be set in motion... }\end{array}$ & $\begin{array}{l}40: 58 \\
41: 09\end{array}$ & $\begin{array}{l}\text { Here I told myself, "Blast!", because again there's "doing-doing-doing", and I } \\
\text { concentrated on what she said, and it disturbed me, so - often I switch off in that case. }\end{array}$ \\
\hline
\end{tabular}

Table 4

Course of experience: example of Student 3.

\begin{tabular}{|c|c|c|}
\hline Time & $\begin{array}{l}\text { No. of } \\
\text { unit }\end{array}$ & Unit \\
\hline $16: 07$ & 26 & Copies the definition while listening to the Teacher's answer and silently questions the invisibility of intellectual activity \\
\hline $16: 18$ & 27 & $\begin{array}{l}\text { Copies the definition while listening to the Teacher, understands that pupils' activity is a visible movement, and is not happy with the } \\
\text { notion }\end{array}$ \\
\hline $16: 24$ & 28 & Copies the definition while listening to the Teacher and understands that pupils' activity may be an invisible mental process \\
\hline $16: 43$ & 29 & Finishes copying the definition while listening to the Teacher and feels confused about the word "doing" \\
\hline
\end{tabular}

teacher's presentation and their former experience of lesson planning and of classroom activities more generally. Discrepancies lead students to engage in forms of inquiry designed to reduce differences, enabling them to understand some aspects of the presentation.

Second, rather than following a unique thread or sequence, the dynamics of student's experience involve a combination of listening 
Table 5

Knowledge elements: example of Student 3.

\begin{tabular}{|c|c|c|}
\hline Time & No. & Knowledge elements \\
\hline 16:07 & 26 & $\begin{array}{l}\text { [giving marks to pupils]: evaluates something that is intellectual } \\
\text { [evaluating]: implies visibility }\end{array}$ \\
\hline $16: 18$ & 27 & $\begin{array}{l}\text { [copying/cutting movements]: are visible } \\
\text { [copying/cutting movements]: are not intellectual } \\
\text { [activity of a pupil]: is rather intellectual }\end{array}$ \\
\hline $16: 24$ & 28 & $\begin{array}{l}\text { [what goes on in the head]: is intellectual } \\
\text { [what goes on in the head]: is not visible } \\
\text { [intellectual activity]: is invisible } \\
\text { [what happens on paper]: is visible }\end{array}$ \\
\hline $\begin{array}{l}16: 43 \\
17: 00\end{array}$ & 29 & [“doing"]:? \\
\hline
\end{tabular}

to the teacher's and other students' talk, reading displayed slides, note-taking and interpreting the dynamic flows generating discrepancies. The different rhythms of continuous talk, discontinuous slide display and their interpretation constrain the dynamics of experience. Backtracking (i.e. retroactively thinking back to what was previously told or displayed) is common, preventing students from simultaneously listening to what they are told in the present.

Third, students' experiences sometimes overlap with teachers' aims so that partial consensuses are reached, though more often than not they diverge significantly (for example, in units 26, 27 and 29 in the case of Student 3). Therefore, there is only a partial understanding of the knowledge as it is presented by the teacher. Particularly in the course studied here, students were found to remain focused on the internal coherence of knowledge without linking it with their future work, even though the teacher sought to show them potential links.

In such a study, we investigate conceptual understanding by tracing successive distinctions that are experienced by subjects. Our approach is similar to the "Knowledge in Pieces" approach (diSessa, 2014) to the extent we identify knowledge elements that relate loosely and unstably and can combine in different ways. However, there are two important differences with this approach. First, we investigate understanding at an intersubjective level. Second, contrarily to the "Knowledge in Pieces" approach, we do not consider that the knowledge elements "exist" in the mind of the individuals, but that they "appear" at a moment in an individual's lived experience.

\section{Discussion: lived experience, a complementary unit of analysis for sociocultural approaches?}

In this paper, we successively defined lived experience as a unit of analysis, specified how to study it, and presented two examples of studies endorsing it. At this point, we can ask how this individual but relational unit of analysis, considering embedment in a material and social environment, but underlie by enactivism, relates to the sociocultural approaches of learning. Fundamentally, experience is lived through by an individual. Even if several subjects act together, each of them live a singular experience that we consider as a different process to be analyzed. Therefore, our unit of analysis may at first seem strictly individual.

Nevertheless, there are some common lineages between enactivism and sociocultural approaches of learning. Varela et al. (1991) claim compatibility between enactivism and situated cognition. Establishing a precise theoretical genealogy is beyond the scope of this paper, but we can have a glimpse on some common origins. Husserl appears to be an important common ancestor. On the enactivist line, from research in biology theorizing the autonomy of living beings, Varela firstly met phenomenology with Merleau-Ponty (Varela et al., 1991) and joins more tightly the Husserlian strand in his later works with some French researchers connecting phenomenology and cognitive sciences (Depraz et al., 2003). On the sociocultural line, Husserl was also an important inspiration for Vygotsky (Macdonald, 2000) and indirectly for ethnomethodology through Schütz's social phenomenology. The phenomenological influences meet the American pragmatism in a common concern of taking into account subjects perspective, which is reflected by the concept of experience in enactivism, and by other concepts in sociocultural approaches (for example, Jean Lave's concept of "setting", subjectobject relation in activity systems model, or "methods" in ethnomethodology). Moreover, both enactivism and sociocultural approaches were developed in opposition to the exclusive cognitive hypothesis of internal information processing. The quest for more global assumptions including the role of the environment in subjects cognition forms another common ground.

Since a certain level of genetic relationship exists between enactivism and sociocultural approaches, we can examine the contact points at the level of our unit of analysis. As lived experience is at one and the same time both active and passive, it arises at a given moment, through particular material and social situations. At times, the material character of the situation appears in the foreground of the experience, such as when the subject uses instruments (e.g. the kickboard and the swimming-pool water in the case of Fanny, cf. Section 4.1). At other times, it is the social nature of the situation that takes centre-stage in the experience when the subject interacts with others (e.g. the teacher's presentation in the case of Student 3, cf. Section 4.2). Lastly, it can happen that material and social aspects are simultaneously prominent in the experience (e.g. when Student 3 listens to another student's question and teacher's answer while copying the definition which is displayed on the screen, cf. Section 4.2).

The experience of each subject forms a whole encompassing and intertwining the individual activity and the material and social situation. Hence each subject constructs her own experience through participation in different communities (school, work, family, 
friends, etc.), through interaction with others and by using a large number of cultural pre-constructs (tools, languages, norms, values, knowledge, techniques, etc.). Each individual experience is socially constituted, and other subjects are to some extent always present. Therefore, we consider each individual experience at every moment as an "individual-social" phenomenon (Theureau, 2006).

Defining lived experience as being intimately related to situations connects it more closely with sociocultural approaches than with cognitive ones. Moreover, it may constitute a way to reduce part of the incompleteness of sociocultural approaches regarding individual aspects of learning. In order to specify this possibility, we can compare our approach with research rooted in the sociocultural tradition in which experience has been already considered as unit of analysis (Jornet et al., 2016; Roth \& Jornet, 2014). Relying on Dewey's concept of experience and Vygotsky's perezhivanie, these authors posit experience as a transactional unit integrating persons, their material and social environment, and the dynamics of their mutual transformations. Its unity forms the base for continuity through time, and allows authors to redefine knowledge transfer in a sociocultural perspective.

Although based on another theoretical framework, our unit of analysis shares a number of commonalities with theirs. First, both units of analysis delineate experience as a process, a transformation unfolding in time. Second, in both, the transformation concerns a whole "person-in-situation" including the intellect, the affect, the body, and the material and social environment. Third, causal explanations are set aside, and experience is viewed as an indeterminate process. Fourth, in both units, the subjects and their material and social environment are intrinsically related. Five, the relation between subjects and environment are both active and passive.

Nevertheless, there are also sharp differences between these two manners of setting experience as a unit of analysis. First of all, in Jornet's and Roth's approach, experience is not an "inchoate flow", but a synthesis of phenomenal configurations close to Dewey's inquiries. It constitutes "an" experience that makes a difference and may entail learning; it can be related to the German concept of Erfahrung. For example, in Jornet et al. (2016), the episode in which a group of students related a dynamic figure with a scientific principle constitute "an" experience. For our part, we strive to study experience as it unfolds, as a pre-reflexive flow, may it appear as incoherent or unproductive. Its synthesis in form of a description (very often a rambling and loosely structured "story") is a consequence of the research. In line with the distinction pointed out by Dilthey, it can be related to the German concept of Erlebnis. For example, in our second empirical case, Student's 3 confusion, leading her to switch off from teacher's presentation (cf. Section 4.2, unit 29) constitute her experience as much as her previous understanding of the invisibility of intellectual activity (cf. unit 28).

Another difference is related to the dialectic between individual and social. As an entry point, Jornet and Roth privilege the social dimension of experience. Even if they acknowledge the possibility of a singular experience for each individual involved in a joint action, they consider that the nature and organization of these singular experiences is of social nature. For them, individual experience appears as a manifestation of social situations, it derives from joint action, which is their primary, generative category. For example, when Jornet et al. (2016) consider the individual experience of students apparently reflecting together on a dynamic figure, they only characterize it regarding its relevance for the current interaction. In the enactivist approach, the social situations are constituted through recursive coordination between individuals, the autonomous coupling defining the own organization of an individual is the primary, generative category, and the entry point is the individual experience. In the same situation of students interacting together, before considering coordination through interaction, we would presuppose that any kind of non-manifest individual experience, such as exploring alone another direction of understanding, feeling annoyed by another student, or imagining what to do on the weekend, may be present among students.

This theoretical difference entails different methodologies. Jornet et al. (2016) adopt the "inward" direction promoted by Greeno (1998): they start the analysis at the collective level of joint action for arriving at the individual level of singular experience. Our approach propose the opposite: it commits researchers to work "outwards" from the individual level of experience to the collective level of activity coordination (Theureau, 2006). Working outward is illustrated in the second empirical case (cf. Section 4.2), where we began by identifying a succession of units and knowledge elements for each individual before identifying articulations and overlaps between them. It allows for the study of the non-manifest activity of individuals and provides a means of revealing, at a collective level, complex imbrications of multiple threads of activity, divergences and misunderstandings. In this view, learning depends on the manner by which the individual processes of lived experience combine through time, in a convergent or in a divergent manner, and form configurations (Veyrunes, Gal-Petitfaux, \& Durand, 2009), that are global forms emerging from the articulation between individual courses of experiences of all the participants. Consequently, rather than bridging the gap between the cognitive and sociocultural approaches to learning and education (Mason, 2007), our unit of analysis paves the way for a sociocultural approach that starts with and from individuals.

Another sharp difference with Jornet's and Roth's approach is related to the difficulty to integrate the concept of knowledge in situative approaches of learning (Lave, 1993). The authors reject the idea of individual knowledge "structure" conceived as a mental representation. Rather, they consider "knowing" as a collective process embedded in joint action, for example when students "apply the pressure and temperature law" (Jornet et al., 2016). In doing so, they align with Lave's proposition to conflate knowledge with the process of activity (Lave, 1993). Our definition of lived experience affords for another way to resolve this difficulty. Knowledge arises in experience in the form of distinctions, of experienced regularities directing action (Maturana, 2000; Maturana \& Varela, 1980); these distinctions concern situations, elements/entities, processes and relations between them. Consequently, in our analysis we can identify how such knowledge elements are successively experienced on the fly by subjects, for example when Student 3 experienced [what goes on in the head] and [what happens on the paper] (cf. Section 4.2). Rooted in the phenomenological dimension of knowledge and learning (Säljö, 2009), our approach allows to consider such knowledge elements at an individual level without separating them from the rich material and social environment in which they are entangled. 


\section{Conclusion}

Endorsing lived experience as a unit of analysis provides a view of learning processes "from within". As a unit of analysis, lived experience is irreducibly individual, but it is also intertwined with the material and social world with which the subject interacts. Learners' lived experience can be studied from a first-person epistemological perspective through using specific second-person methods such as explicitation and self-confrontation interviews. Such an approach may be used in any learning situation to highlight the singular and sometimes surprising path of what is perceived, felt, understood or interpreted by subjects.

Using experience as a unit of analysis implies adopting the point of view of the subject as a reference. The point is to describe learning neither from the perspective of the knowledgeable subject nor from the perspective of formalized knowledge. Rather, the aim is to understand subject epistemology - her way of making knowledge emerges. This implies reconstructing the dynamics of the learner's coupling with her environment, even if it is not valid from the point of view of the teacher or trainer. In this view, what is seen as an error or misconception may in fact be described positively as a form of activity, a disposition to act that has a proper consistency. Thus, the teacher or trainer should not consider that $\mathrm{s}$ /he makes the learner enter in a prescriptive world of instructions, tasks, tools and predetermined knowledge. Rather, s/he should act in a sceptical way, and suspend her habitual judgements by considering them as part of her experience.

\section{Acknowledgements}

The authors are grateful to the Aslan (ANR-10-LABX-0081) of Universite de Lyon, for its financial support, they also thank the Pedagogical High School of canton Vaud for translating this text from the French. Thanks also to Abdoulaye Faye for his readings of successive manuscripts.

\section{Funding} (ANR).

Program "Investissements d'Avenir" (ANR-11-IDEX-0007) of the French government operated by the National Research Agency

\section{References}

Alexander, P. A. (2007). Bridging cognition and socioculturalism within conceptual change research: Unnecessary foray or unachievable feat? Educational Psychologist, 42(1), 67-73.

Bitbol, M. (2014). L'expérience d'objectiver (ou comment vivre en première personne la possibilité de la troisième). In N. Depraz (Ed.), Première, deuxième, troisìeme personne. Bucarest: Zeta Books.

Depraz, N. (2012). Empathy and second-person methodology. Continental Philosophy Review, 45(3), 447-459. https://doi.org/10.1007/s11007-012-9223-z.

Depraz, N., Varela, F. J., \& Vermersch, P. (2003). On becoming aware: A pragmatics of experiencing. Amsterdam: John Benjamins Publishing.

Derry, S. J., Pea, R. D., Barron, B., Engle, R. A., Erickson, F., Goldman, R., \& Sherin, B. L. (2010). Conducting video research in the learning sciences: Guidance on selection, analysis, technology, and ethics. Journal of the Learning Sciences, 19(1), 3-53. https://doi.org/10.1080/10508400903452884.

Dieumegard, G., \& Perrin, N. (2014). Understanding and mind wandering. An account of the silent conceptual experiences of the students. In Communication at the 9th international conference on conceptual change.

diSessa, A. A. (2014). The construction of causal schemes: Learning mechanisms at the knowledge level. Cognitive Science, 38(5), 795-850. https://doi.org/10.1111/ cogs.12131.

Giorgi, A. (2014). Phenomenological philosophy as the basis for a human scientific psychology. The Humanistic Psychologist, 42, $233-248$.

Greeno, J. G. (1998). The situativity of knowing, learning, and research. American Psychologist, 53(1), 5-26. https://doi.org/10.1037/0003-066X.53.1.5.

Heidegger, M. (1971). On the way to language. New York: Harper \& Row.

Henry, M. (2008). Material phenomenology. New York: Fordham University Press.

Hurlburt, R. T., \& Schwitzgebel, E. (2007). Describing inner experience? Proponent meet skeptic. Cambridge (MA: MIT Press.

de Jaegher, H. (2015). How we affect each other. Michel Henry's « pathos-with » and the enactive approach to intersubjectivity. Journal of Consciousness Studies, 22 $(1-2), 112-132$.

Jordan, B., \& Henderson, A. (1995). Interaction analysis: Foundations and practice. Journal of the Learning Sciences, 4(1), 39-103. https://doi.org/10.1207/ s15327809j1s0401_2.

Jornet, A., Roth, W.-M., \& Krange, I. (2016). A transactional approach to transfer episodes. Journal of the Learning Sciences, 25(2), 285-330. https://doi.org/10.1080/ 10508406.2016.1147449.

Lave, J. (1993). The practice of learning. In J. Lave, \& S. Chaiklin (Eds.), Understanding practice: Perspectives on activity and context (pp. 3-32). Cambridge (MA: Cambridge University Press.

Lémonie, Y., Light, R., \& Sarremejane, P. (2016). Teacher-student interaction, empathy and their influence on learning in swimming lessons. Sport, Education and Society, 21(8), 1249-1268. https://doi.org/10.1080/13573322.2015.1005068.

Lyle, J. (2003). Stimulated recall: A report on its use in naturalistic research. British Educational Research Journal, 29(6), 861-878. https://doi.org/10.1080/ 0141192032000137349.

Macdonald, P. S. (2000). Phenomenological factors in Vygostky's mature psychology. History of the Human Sciences, 13(3), 69-93.

Mason, L. (2007). Introduction: Bridging the cognitive and sociocultural approaches in research on conceptual change: Is it feasible? Educational Psychologist, 42(1), $1-7$.

Maturana, H. (2000). The nature of the laws of nature. Systems Research and Behavioral Science, 17(5), 459-468. https://doi.org/10.1002/1099-1743(200009/10)17: 5<459::AID-SRES371>3.0.CO;2-I.

Maturana, H. R., \& Varela, F. J. (1980). Autopoiesis and cognition: The realization of the living. New York: Boston Studies in the Philosophy of Science.

Mc Carthy, J., \& Wright, P. (2004). Technology as experience. Cambridge (MA): MIT Press.

McAuliffe, A., \& McGann, M. (2016). Sampling participants' experience in laboratory experiments: Complementary challenges for more complete data collection. Frontiers in Psychology, 7. https://doi.org/10.3389/fpsyg.2016.00674.

Nagel, T. (1974). What is it like to be a bat? The Philosophical Review, 83(4), 435-450.

Nisbett, R. E., \& Wilson, T. D. (1977). Telling more than we can know: Verbal reports on mental processes. Psychological Review, 84(3), 231. https://doi.org/10.1037/ 0033-295X.84.3.231.

Pauen, M. (2012). The second-person perspective. Inquiry, 55(1), 33-49. https://doi.org/10.1080/0020174X.2012.643623. 
Petitmengin, C. (2006). Describing one's subjective experience in the second person: An interview method for the science of consciousness. Phenomenology and the Cognitive Sciences, 5(3-4), 229-269. https://doi.org/10.1007/s11097-006-9022-2.

Petitmengin, C., Remillieux, A., Cahour, B., \& Carter-Thomas, S. (2013). A gap in Nisbett and Wilson's findings? A first-person access to our cognitive processes. Consciousness and Cognition, 22(2), 654-669. https://doi.org/10.1016/j.concog.2013.02.004.

Piaget, J. (1976). The grasp of consciousness. Action and concept in the young child. Cambridge (MA: Harvard University Press.

Roth, W.-M., \& Jornet, A. (2014). Toward a theory of experience. Science Education, 98(1), 106-126. https://doi.org/10.1002/sce.21085.

Säljö, R. (2009). Learning, theories of learning, and units of analysis in research. Educational Psychologist, 44(3), 202-208. https://doi.org/10.1080/ 00461520903029030 .

Sfard, A. (1998). On two metaphors for learning and the dangers of choosing just one. Educational Researcher, 27(2), 4-13. https://doi.org/10.3102/ 0013189X027002004.

Stern, D. N. (2004). The present moment in psychotherapy and everyday life. New York: W. W. Norton \& Company.

Theureau, J. (2006). Le cours d'action: Méthode développée. Toulouse: Octarès.

Theureau, J. (2010). Les entretiens d'autoconfrontation et de remise en situation par les traces matérielles et le programme de recherche « cours d'action ». Revue d'anthropologie des connaissances (Vol 4, 2,(2), 287. https://doi.org/10.3917/rac.010.0287.

Varela, F. J. (1999). Present-time consciousness. Journal of Consciousness Studies, 6(2-3), 111-140.

Varela, F. J., Thompson, E., \& Rosch, E. (1991). The embodied mind: Cognitive science and human experience. Cambridge (MA: MIT press.

Vermersch, P. (1994). L'entretien d'explicitation en formation continue et initiale. Paris: ESF.

Vermersch, P. (2000). Approche du singulier. In J.-M. Barbier (Ed.), L'analyse de la singularité de l'action (pp. 239-256). Paris: PUF.

Vermersch, P. (2012). Explicitation et phénoménologie: vers une psychophénoménologie. Paris: PUF.

Veyrunes, P., Gal-Petitfaux, N., \& Durand, M. (2009). Configurations of activity: From the coupling of individual actions to the emergence of collective activity. A study of mathematics teaching situation in primary school. Research Papers in Education, 24(1), 95-113. https://doi.org/10.1080/02671520801945784. 